\title{
Overexpression of GLUT1 correlates with Kras mutations in lung carcinomas
}

\author{
HIDEFUMI SASAKI, MASAYUKI SHITARA, KEISUKE YOKOTA, YU HIKOSAKA, \\ SATORU MORIYAMA, MOTOKI YANO and YOSHITAKA FUJII \\ Department of Oncology, Immunology and Surgery, Nagoya City University, \\ Graduate School of Medical Sciences, Mizuho-cho, Mizuho-ku, Nagoya 467-8601, Japan
}

Received October 14, 2011; Accepted December 13, 2011

DOI: $10.3892 / \mathrm{mmr} .2011 .736$

\begin{abstract}
Glucose is the major source of energy for cells, and glucose transporter 1 (GLUT1) is the most common glucose transporter. GLUT1 has been found to be aberrantly expressed in several tumor types. From the results of the microarray and serial analysis of gene expression (SAGE), GLUT1 transcript expression was found to be higher in clones with mutant Kras alleles. We hypothesized that GLUT1 overexpression might be correlated with clinicopathological features of Japanese lung cancers. Immunohistochemistry for GLUT1 was performed in 283 surgically treated non-small cell lung cancer (NSCLC) cases from Nagoya City University Hospital. Thirty-six Kras mutant carcinoma cases were included. GLUT1 overexpression was found in 138 (48.8\%) lung cancer patients. The GLUT1 overexpression status was significantly correlated with gender (women $31.9 \%$ vs. men $54.5 \%, \mathrm{P}<0.0001$ ), smoking status (never smoker $31.4 \%$ vs. smoker $59.4 \%, \mathrm{P}<0.0001$ ) and pathological subtypes (adenocarcinoma $36.4 \%$ vs. non-adenocarcinoma $74.5 \%, \mathrm{P}<0.0001)$. In addition, the GLUT1 overexpression status was significantly correlated with gene mutation status, including EGFR (mutation-positive $23.4 \%$ vs. -negative $58.3 \%$, $\mathrm{P}<0.0001$ ) and Kras (mutation-positive $66.7 \%$ vs. -negative $46.6 \%, \mathrm{P}=0.038)$. The survival of patients with GLUT1 overexpression ( $n=137,50$ were deceased) was significantly worse when compared to the patients with normal expression of GLUT1 ( $n=142,31$ were deceased) (Log-rank test, $\mathrm{P}=0.0009)$. Thus, GLUT-1 overexpression correlates with an aggressive phenotype of lung carcinoma.
\end{abstract}

Correspondence to: Dr Hidefumi Sasaki, Department of Immunology, Oncology and Surgery, Nagoya City University, Graduate School of Medical Sciences, 1 Kawasumi, Mizuho-cho, Mizuho-ku, Nagoya 467-8601, Japan

E-mail: hisasaki@med.nagoya-cu.ac.jp

Key words: glucose transporter 1, lung cancer, Kras, EGFR, prognosis

\section{Introduction}

Despite recent improvements in diagnosis, lung cancer is a major cause of death from malignant diseases, due to its high incidence, malignant behavior and lack of major advancements in treatment strategy (1). Lung cancer was the leading indication for respiratory surgery (46.7\%) in 2007 in Japan (2). More than 25,000 patients underwent surgical operation at Japanese institutions in 2007 (2). The clinical behavior of lung cancer is largely associated with its stage. Cure of lung cancer by surgery is only achieved in cases of early stage disease (3).

The oxidation of glucose generates a major source of metabolic energy in eukaryotic cells (4). Glucose regulates transcription, enzyme activity, hormone secretion and the activity of gluco-regulated neurons. These functions typically are secondary to glucose uptake, which is controlled primarily by the glucose transporter family, GLUTs (5). There are 14 GLUT members (6). Glucose transporter 1 (GLUT1), the first member of the GLUT family to be identified, has been the most extensively studied. GLUT1 was reported to be overexpressed in a variety of cancers, including hepatic, pancreatic, breast, colorectal, ovarian and lung (7-11). Furthermore, GLUT1 positivity in malignant cells revealed by immunohistochemistry indicates increased proliferative activity, energy requirements and aggressive behavior $(12,13)$. More recently, glucose deprivation was found to contribute to the development of Kras pathway mutations in colorectal cancer cells (14). The Kras somatic mutation is well investigated in lung cancers (15), and mutations of the Kras gene occur in approximately $10 \%$ of Japanese non-small cell lung carcinomas (NSCLCs) (16).

Although GLUT1 protein expression has been investigated in lung cancers (17), the association of the Kras gene and GLUT1 status in Japanese lung cancer has not been previously reported. To determine the GLUT1 status in Japanese lung carcinomas, we investigated GLUT1 by immunohistochemistry. The findings were compared to the clinicopathologic features of the lung cancers.

\section{Patients and methods}

Patients. The study group included 283 lung cancer patients who had undergone surgery at the Department of Surgery II, 
Nagoya City University Medical School, between 2001 and 2008. All tumor samples were immediately frozen and stored at $-80^{\circ} \mathrm{C}$ until assayed.

The clinical and pathological characteristics of the 283 lung cancer patients were as follows, 161 cases at stage I, 45 at stage II and 77 at stage III-IV. The mean age was 65.6 years (range, 29-86). Among the 283 lung cancer patients, 96 were non-smokers, 189 were male and 188 were diagnosed as adenocarcinoma. The samples from these patients had been previously sequenced for EGFR (18-21).

PCR assays for Kras. Total-RNA was extracted from lung cancer tissues using the Isogen kit (Nippon Gene, Tokyo, Japan) according to the manufacturer's instructions. RNA concentration was determined by a NanoDrop spectrophotometer (NanoDrop Technologies, Ind. Rockland, DE, USA) and adjusted to a concentration of $200 \mathrm{ng} / \mathrm{ml}$. RNA ( $1 \mu \mathrm{g})$ was reverse transcribed by Superscript II enzyme (Gibco BRL, Gaithersburg, MD, USA) with $0.5 \mu \mathrm{g}$ oligo(dT) ${ }_{12-16}$ (Amersham Pharmacia Biotech Inc., Piscataway, NJ, USA). DNA concentration was determined by NanoDrop and adjusted to $50 \mathrm{ng} / \mathrm{ml}$. We used $1 \mu 1$ of each DNA for LightCycler assays (21). Kras gene primers were forward, 5'AGAGAGGCCTGCTGAAAAT3' and reverse, 5'AATTTGTTCTCTATAATGGTGAATATC-3', and were amplified. For the genotyping, sensor LC Red 640-CTACGCCACCAGCTCCAAC and anchor TCCACAAA ATGATTCTGAATTAGCTGTATCGTCAAGGCACTCTTGfluorescein probes were used. The cycling conditions were as follows, initial denaturation at $95^{\circ} \mathrm{C}$ for $2 \mathrm{~min}$, followed by 40 cycles at $94^{\circ} \mathrm{C}$ for $1 \mathrm{sec}, 55^{\circ} \mathrm{C}$ for $10 \mathrm{sec}$ and $72^{\circ} \mathrm{C}$ for $7 \mathrm{sec}$.

Immunohistochemistry. GLUT1 protein expression was evaluated by IHC using ready-to use anti-GLUT1 antibody (SPM498, mouse monoclonal; Thermo Scientific, Rockford, IL, USA). We used a standard protocol for the immunostaining of the samples. Sections $(4 \mu \mathrm{m})$ were made from paraffin tissue blocks from NSCLC tumors. The slides were treated with xylenes, and then dehydrated in alcohol. For epitope retrieval, specimens were exposed to $10 \mu \mathrm{M}$ citrate buffer ( $\mathrm{pH}$ 6.0) and heated for $10 \mathrm{~min}$ in a microwave. Endogenous peroxidase activity was blocked with $\mathrm{H}_{2} \mathrm{O}_{2}$ in methanol. Sections were incubated with blocking solution (10\% Block Ace) and then reacted with the ready-to use antibody overnight at $4^{\circ} \mathrm{C}$. After the excess antibody had been washed out with phosphate-buffered saline (PBS), samples were incubated with a peroxidase-conjugated anti-mouse antibody (Mouse HRP EnVision ${ }^{\mathrm{TM}}{ }^{\mathrm{T}}$; Dako Co., Carpinteria, CA, USA) for $45 \mathrm{~min}$. After the excess antibody had been washed out with PBS, 3,3-diaminobenzidine (DAB) substrate $(10 \mathrm{~min})$ was used to visualize the antibody binding, and the sections were counterstained with hematoxylin. GLUT1 staining was evaluated under a light microscope at x400 magnification.

Statistical methods. Statistical analyses were conducted using the Mann-Whitney U test for unpaired samples and Wilcoxon signed-rank test for paired samples. Linear relationships between variables were determined by means of simple linear regression. Correlation coefficients were determined by rank correlation using the Spearman's test and Chi-square test. The overall survival of lung cancer patients was examined by the Kaplan-Meier methods, and differences were examined by the Log-rank test. All analysis was carried out using the Stat-View software package (Abacus Concepts Inc., Berkeley, CA, USA). A P-value $<0.05$ was considered to indicate statistical significance.

\section{Results}

GLUT1 expression status in Japanese lung cancer patients. Using the immunohistochemical analysis for GLUT1 from 283 lung cancer patients, 138 sections (48.8\%) had positive staining for GLUT1 (Fig. 1). The clinicopathological features of the patients are shown in Table I. GLUT1 expression status was significantly correlated with gender (male $56.5 \%$ vs. female $30.2 \%, \mathrm{P}<0.0001$ ), tobacco-smoking (non-smokers $28.1 \%$ vs. smokers 59.4\%, $\mathrm{P}<0.0001$ ), pathological subtypes (adenocarcinoma $36.2 \%$ vs. non-adenocarcinoma $74.5 \%, \mathrm{P}<0.0001$ ), and pathological stages (stage I $36.4 \%$ vs. stages II-IV $65.3 \%$, $\mathrm{P}<0.0001)$, but not with age $(<65$ vs. $\geq 65, \mathrm{P}=0.2315)$. In addition, the GLUT1 overexpression status was significantly correlated with the gene mutation status, including EGFR (mutation-positive $23.4 \%$ vs. -negative $58.3 \%, \mathrm{P}<0.0001$ ) and Kras (mutation-positive $66.7 \%$ vs. -negative $46.6 \%, \mathrm{P}=0.038$ ). The overall survival of 279 lung cancer patients from Nagoya City University, with follow-up through August 31, 2011, was studied in reference to the GLUT1 status. The survival of the patients with increased GLUT1 positivity $(n=137,50$ were deceased) was significantly worse when compared to the patients with normal GLUT1 expression $(n=142$, 31 were deceased) (Log-rank test, $\mathrm{P}=0.0009$ ) (Fig. 2).

\section{Discussion}

In this analysis, we found increased GLUT1 protein expression in $48.4 \%$ of the Japanese lung cancers. The GLUT1 gene status was correlated with advanced stage and Kras mutations in the lung cancers.

Glucose transporters, such as GLUT1, mediate basal glucose transport in cancer cells, regulating the maintenance of energy metabolism in cells in regions of limited supply (22). Hypoxia is a hallmark of various types of cancers and is often associated with disease progression. This process occurs when tumors outgrow the existing vasculature. Tumors respond to hypoxic conditions by activating genes that regulate glycolysis and glucose transport (23). Malignant cells require a high energy level through glycolytic generation of ATP to proliferate and survive. In cancer-induced starvation, GLUT1 overexpression governs mechanisms that favor tumor growth at the expense of host tissues $(24,25)$. Thus, we examined GLUT1 expression, as higher levels of GLUT1 in cancer indicate a poor prognosis $(26,27)$.

Mutations in oncogenes endow cancer cells with the ability to outgrow their neighboring cells in situ (28). Mutations in Kras commonly occur in some form of lung cancers $(15,16,29)$, and Kras mutations are correlated with lung cancer prognosis $(15,16)$. From the results of the microarray and SAGE expression analyses, GLUT1 transcript expression was higher in the clones with mutant Kras alleles (14). These results were also confirmed through quantitative polymerase chain reaction (14). GLUT1 
Table I. Clinicopathological data of the 283 lung cancer patients.

\begin{tabular}{|c|c|c|c|}
\hline \multirow[b]{2}{*}{ Factors } & \multicolumn{2}{|c|}{ GLUT1 expression status } & \multirow[b]{2}{*}{ P-value } \\
\hline & $\begin{array}{c}\text { Positive patients } \\
\mathrm{n}(\%)\end{array}$ & $\begin{array}{c}\text { Negative patients } \\
\mathrm{n}(\%)\end{array}$ & \\
\hline Mean age (years) $\quad 66.3 \pm 10.4$ & $68.3 \pm 6.7$ & $65.4 \pm 11.7$ & 0.1965 \\
\hline \multicolumn{4}{|l|}{ Stage } \\
\hline $\mathrm{I}$ & $57(43.4)$ & 104 (71.6) & \multirow[t]{2}{*}{$<0.0001$} \\
\hline II-IV & $81(56.6)$ & $41(28.4)$ & \\
\hline \multicolumn{4}{|l|}{ EGFR mutations } \\
\hline Positive & $18(13.0)$ & $59(40.7)$ & \multirow[t]{2}{*}{$<0.0001$} \\
\hline Negative & $120(87.0)$ & $86(59.3)$ & \\
\hline \multicolumn{4}{|l|}{ Smoking status } \\
\hline Never-smoker & $27(19.6)$ & $69(47.6)$ & \multirow[t]{2}{*}{$<0.0001$} \\
\hline Smoker & $111(80.4)$ & $76(52.4)$ & \\
\hline \multicolumn{4}{|l|}{ Kras mutation } \\
\hline Positive & $20(33.3)$ & $10(6.9)$ & \multirow[t]{2}{*}{0.038} \\
\hline Negative & $118(66.7)$ & $135(93.1)$ & \\
\hline \multicolumn{4}{|l|}{ Pathological subtype } \\
\hline Adenocarcinoma & $68(49.3)$ & $121(83.4)$ & \multirow[t]{2}{*}{$<0.0001$} \\
\hline Non-adenocarcinoma & $70(50.7)$ & $24(16.6)$ & \\
\hline \multicolumn{4}{|l|}{ Age (years) } \\
\hline$<65$ & $56(40.6)$ & $70(48.3)$ & \multirow[t]{2}{*}{0.3963} \\
\hline$\geq 65$ & $82(59.4)$ & $75(51.7)$ & \\
\hline \multicolumn{4}{|l|}{ Gender } \\
\hline Male & $108(78.3)$ & $81(55.9)$ & \multirow[t]{2}{*}{$<0.0001$} \\
\hline Female & $30(21.7)$ & $64(44.1)$ & \\
\hline
\end{tabular}

\section{Glut1 expression by immunohistochemistry}

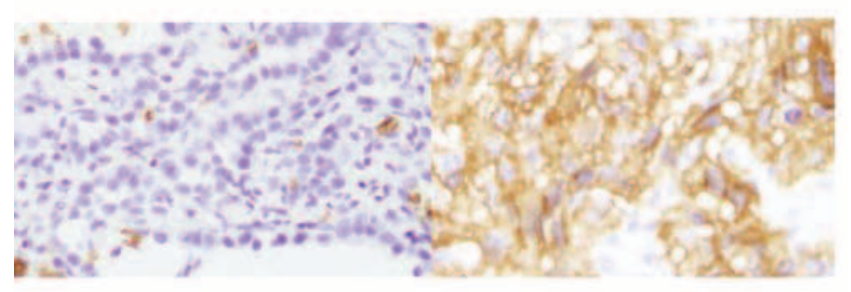

Negative case

\section{Positive case}

Figure 1. Using immunohistochemical analysis for GLUT1, in samples from 283 lung cancer patients, 138 sections $(48.8 \%)$ were positively stained for GLUT1. Left, negative case; right, positive case.

transcript expression is consistently higher, ranging from 3- to 22-fold, in clones with mutant Kras alleles compared to isogenic clones with wild-type alleles (14). Actually, the upregulation of GLUT1 was found to be accompanied by a significant increase in glucose uptake in all cells with mutant Kras alleles compared to isogenic cells with wild-type alleles (14). A role for metabolic abnormalities in cancer has become increasingly recognized

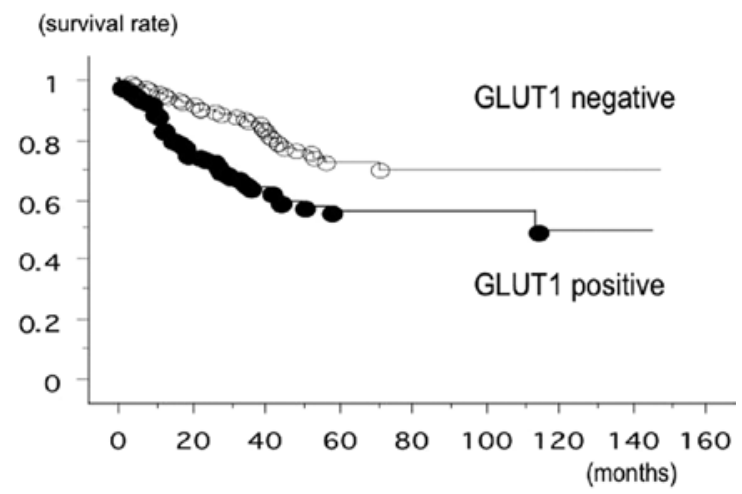

Figure 2. Survival of patients with increased GLUT1 positivity $(n=137,50$ were deceased) was significantly worse when compared to the patients with normal GLUT1 expression $(n=142,31$ were deceased) (Log-rank test, $P=0.0009)$.

(30,31). Insightful hypotheses concerning the manifold ways in which metabolic abnormalities can promote tumor progression have also been presented (32-34).

In summary, GLUT1 overexpression was found to be correlated with an aggressive phenotype of lung carcinoma, 
such as advanced stage and Kras mutations. GLUT may be a molecular target for advanced lung cancers.

\section{Acknowledgements}

The authors would like to thank Mrs Akiha Kuramoto and Miki Mochizuki for their excellent technical assistance. This study was supported by Grants-in-Aid for Scientific Research, Japan Society for the Promotion of Science (JSPS) (nos. 19390367, 21390394, 21591820) and a grant for Cancer Research Program for Developing the Supporting System for Upgrading Education and Research (2009) from the Ministry of Education, Culture, Sports, Science and Technology of Japan.

\section{References}

1. Ginsberg RJ, Kris MK and Armstrong JG: Cancer of the Lung: Principles and Practice of Oncology. 4th edition, Lippincott, Philadelphia, pp673-682, 1993.

2. Ueda Y, Fujii Y and Kuwano H: Thoracic and cardiovascular surgery in Japan during 2007. Annual report by the Japanese Association for Thoracic Surgery. Gen Thorac Cardiovasc Surg 57: 488-513, 2009.

3. Postus PE, on behalf of the Lung Cancer Cooperative Group of the EORTC: The experience of the Lung Cancer Cooperative Group of the European Organization for Research and Treatment of Cancer. Chest (Suppl 113): S28-S31, 1997.

4. Isselbacher KJ: Sugar and amino acid transport by cells in culture-differences between normal and malignant cells. N Engl J Med 286: 929-933, 1972.

5. Thorens B and Mueckler M: Glucose transporters in the 21st Century. Am J Physiol Endocrinol Metab 298: E141-E145, 2010.

6. Suganuma N, Segade F, Matsuzu K and Bowden DW: Differential expression of facilitative glucose transporters in normal and tumor kidney tissues. BJU Int 99: 1143-1149, 2007.

7. Yamamoto T, Seino Y, Fukumoto H, et al: Over-expression of facilitative glucose transporter genes in human cancer. Biochem Biophys Res Commun 170: 223-230, 1990.

8. Brown RS and Wahl RL: Overexpression of GLUT-1 glucose transporter in human breast cancer. An immunohistochemical study. Cancer 72: 2979-2985, 1993.

9. Haber RS, Rathan A and Weiser KR: GLUT-1 glucose transporter expression in colorectal carcinoma: a marker for poor prognosis. Cancer 83: 34-40, 1998.

10. Cantuaria G, Fagotti A and Ferrandina G: GLUT-1 expression in ovarian carcinoma: association with survival and response to chemotherapy. Cancer 92: 1144-1150, 2001.

11. Ogawa J, Inoue H and Koide S: Glucose-transporter-type-I-gene amplification correlates with sialyl-Lewis-X synthesis and proliferation in lung cancer. Int J Cancer 74: 189-192, 1997.

12. Birnbaum MJ, Haspel HC and Rosen OM: Cloning and characterization of a cDNA encoding the rat brain glucose-transporter protein. Proc Natl Acad Sci USA 83: 5784-5788, 1986.

13. Fukumoto H, Seino S, Imura H, Seino Y and Bell GI: Characterization and expression of human HepG2/erythrocyte glucose transporter gene. Diabetes 37: 657-661, 1988.

14. Yun J, Rago C, Cheong I, et al: Glucose deprivation contributes to the development of Kras pathway mutations in tumor cells. Science 325: 1555-1559, 2009.
15. Sasaki H, Hikosaka Y, Kawano O, et al: Evaluation of Kras gene mutation and copy number gain in non-small cell lung cancer. $\mathrm{J}$ Thorac Oncol 6: 15-20, 2011.

16. Sasaki H, Okuda K, Kawano O, et al: Nras and Kras mutation in Japanese lung cancer patients: Genotyping analysis using LightCycler. Oncol Rep 18: 623-628, 2007.

17. Usuda K, Sagawa M, Aikawa H, et al: Correlation between glucose transporter-1 expression and 18F-fluoro-2-deoxyglucose uptake on positron emission tomography in lung cancer. Gen Thorac Cardiovasc Surg 58: 405-410, 2010.

18. Sasaki H, Shimizu S, Endo K, et al: EGFR and erbB2 mutation status in Japanese lung cancer patients. Int J Cancer 118: 180-184, 2006.

19. Endo K, Konishi A, Sasaki H, et al: Epidermal growth factor receptor gene mutation in non-small cell lung cancer using highly sensitive and fast TaqMan PCR assay. Lung Cancer 50: 375-384, 2005.

20. Sasaki H, Endo K, Konishi A, et al: EGFR mutation status in Japanese lung cancer patients: genotyping analysis using LightCycler. Clin Cancer Res 11: 2924-2929, 2005.

21. Endo K, Sasaki H, Yano M, et al: Evaluation of the epidermal growth factor receptor gene mutation and copy number in non-small cell lung cancer with gefitinib therapy. Oncol Rep 16: 533-541, 2006

22. Kallinowski F, Schlenger KH, Kunkel S, Kloes M, Stohrer M, Okunieff P and Vaupel P: Blood flow, metabolism, cellular microenvironment and growth rate of human tumor xenography. Cancer Res 49: 3759-3764, 1989.

23. Chiche J, Brahimi-Horn MC and Pouyssegur J: Tumor hypoxia induces a metabolic shift causing acidosis: a common feature in cancer. J Cell Mol Med 14: 771-794, 2010.

24. Heber D, Byerley LO and Tchekmedyian NS: Hormonal and metabolic abnormalities in the malnourished cancer patients: effects on host-tumor interaction. JPEN J Parenter Enteral Nutr 16 (Suppl 6): S60-S64, 1992.

25. Macheda ML, Rogers S and Best JD: Molecular and cellular regulation of glucose transporter (GLUT) proteins in cancer. J Cell Physiol 202: 654-662, 2005.

26. Smith TA: Facilitative glucose transporter expression in human cancer tissue. Br J Biomed Sci 56: 285-292, 1999.

27. Airley RE and Mobasheri A: Hypoxic regulation of glucose transport, anaerobic metabolism and angiogenesis in cancer: novel pathways and targets for anticancer therapeutics. Chemotherapy 53: 233-256, 2007 .

28. Vogelstein B and Kinzler KW: Cancer genes and the pathways they control. Nat Med 10: 789-799, 2004.

29. Kiaris H and Spandidos DA: Mutations of ras genes in human tumors (Review). Int J Oncol 7: 413-421, 1995.

30. Kim JW, Gao P and Dang CV: Effects of hypoxia on tumor metabolism. Cancer Metastasis Rev 26: 291-298, 2007.

31. Gatenby RA and Gillies RJ: Who do cancers have high aerobic glycolysis? Nat Rev Cancer 4: 891-899, 2004.

32. Gillies RJ, Robey I and Gatenby RA: Causes and consequences of increased glucose metabolism of cancers. J Nucl Med 49 (Suppl 2): S24-S42, 2008

33. Hsu PP and Sabatini DM: Cancer cell metabolism: Warburg and beyond. Cell 134: 703-707, 2008.

34. Vander Heiden MG,Cantley LC and Thompson CB: Understanding the Warburg effect: the metabolic requirements of cell proliferation. Science 324: 1029-1033, 2009. 